\title{
Use of the uterine manipulator in minimally invasive surgery for endometrial cancer. Oncological outcomes
}

\author{
María Cuadra and Iñaki Lete* \\ Gynaecology Oncology Unit, Araba University Hospital, Vitoria, Spain
}

\begin{abstract}
Objective: To analyse the differences in oncological outcomes in patients operated for endometrial cancer based on the use of a uterine manipulator.

Methods: Retrospective study of patients underwent surgery for endometrial carcinoma in a single centre, a tertiary hospital that has a gynaecological oncology unit. Data were collected from patients undergoing minimally invasive surgery for endometrial carcinoma in the period between January 1, 2010 and December 31, 2020. The sample was divided into two groups: Group A, made up of patients in whom a uterine manipulator was used during surgery, and Group B, made up of women in whom no manipulator was used.

Results: We included 279 patients with minimally invasive approach (either laparoscopic surgery or robotic surgery). In 232 patients (Group A, 83,1\%), a uterine manipulator, V-Care was used, while in 47 patients (Group B, 16.9\%) the manipulator was not used. No differences were observed in oncological outcomes between the groups (Disease Free Survival [DFS] 39,1 months in Group A and 39,0 months in Group B).
\end{abstract}

Conclusion: Our results confirm that the uterine manipulator can be used safely during surgery for endometrial carcinoma.

\section{Introduction}

Endometrial carcinoma is the most common tumour of the female genital tract in developed countries [1]. The treatment of endometrial cancer is based on the performance of a hysterectomy and bilateral salpingoooforectomy [2]. Until a few years ago, the surgical approach to endometrial cancer was carried out through a laparotomy, but with the advent of laparoscopy, surgery for this type of carcinoma was soon started in this way. Laparoscopic access or through minimally invasive surgical techniques has proven to be effective and safe, from the oncological point of view for patients with the disease [3] .

To perform a laparoscopic total hysterectomy, the use of a uterine manipulator is helpful during the procedure [4].

In our centre, we systematically perform the surgical approach to endometrial cancer by a minimally invasive approach, starting in 2010 . During the first years we used a uterine manipulator in all cases, until in 2018 the results of the LAAC study were published, referring to cervical cancer, in which oncological results were significantly worse in patients undergoing minimally invasive surgery [5]. One of the reasons that may explain the worse results in the group of women undergoing laparoscopy is the use of a uterine manipulator [6]

From the beginning of 2019, we decided to stop using the uterine manipulator in patients operated, by laparoscopic or robotic route, for endometrial carcinoma. In this study, we intend to analyse the oncological results of the patients operated on in our centre based on the use of the uterine manipulator.

\section{Material and methods}

\section{Design}

This is a retrospective study of patients operated on in a single centre, a tertiary hospital that has a gynaecological oncology unit. Data were collected from patients undergoing minimally invasive surgery for endometrial carcinoma in the period between January 1, 2010 and December 31, 2020.

The sample was divided into two groups: Group A, made up of patients in whom a uterine manipulator was used during surgery, and Group B, made up of women in whom no manipulator was used.

In our centre, we always use the V-Care manipulator (ConMed, Utica, NY, USA)). The manipulator is usually placed under direct vision once the laparoscopic or robotic trocars have been introduced.

In cases where we have not used the uterine manipulator, we insert a gauze into the vagina at the time of colpotomy and push it with a surgical forceps so that the limit between the cervix, vagina and bladder is visible.

\section{Variables}

For the study, a database was designed in Excel format in which demographic data of the patients, pre- and post-surgical stage, type of intervention performed, use of the uterine manipulator, complementary treatment, recurrence rate and death rate and survival were collected. Disease free survival (DFS) and overall survival (OS) were also calculated and expressed in months.

${ }^{\star}$ Correspondence to: Iñaki Lete, MD, Obstetrics and Gynaecology Clinical Management Unit, Araba University Hospital, José Atxotegi s/n. 01009 Vitoria, Spain, E-mail: luisignacio.letelasa@osakidetza.eus

Key words: endometrial carcinoma, laparoscopy, robotics, uterine manipulator, disease free survival, overall survival

Received: January 16, 2021; Accepted: January 25, 2021; Published: February 01, 2021 


\section{Statistical analysis}

Data were collected using a data collection sheet specifically designed for the study. The database included ranges and internal consistency rules to guarantee quality control of the data.

All the analyses were carried out from a single sample of assessable patients that included all those patients who met the selection criteria and presented data on the main study variables.

Categorical variables were described as absolute and relative frequencies. For continuous variables, the mean, SD, median, mode, minimum, maximum, and total number of valid values were calculated. Parametric tests (Student's t-test or ANOVA) were used to compare subgroups of patients. The $X^{2}$ test was performed for qualitative variables. SAS version 9.1 (SAS Institute, Cary, NC, USA) was used to carry out the statistical analyses.

\section{Ethics}

The Spanish health authorities allow that since it is a retrospective study, in which the patients are anonymized, it is not necessary for each patient to sign a specific informed consent for the study.

\section{Results}

In the period analysed, we have operated on 329 patients affected by endometrial carcinoma. In 279 patients $(85 \%)$, the approach was minimally invasive (either laparoscopic surgery or robotic surgery). In 232 patients (Group A, 83,1\%), a uterine manipulator, V-Care was used, while in 47 patients (Group B, 16.9\%) the manipulator was not used.

Table 1 shows the characteristics of the two populations analysed, noting that there are no differences between the two, except in the fact that in the group A there were more stages I endometrial carcinomas $(89.6 \%)$ than in the group B $(74.4 \%)$ (p value $<0.05)$.

Table 2 shows the oncological outcomes of the patients. We did not observe significant differences between the two groups, except for the fact that more patients in the group $\mathrm{B}$ received complementary treatment $(65.9 \%$ versus $49.5 \%$; $\mathrm{p}$ value $<0.05)$.

Recurrence and mortality rates, as well as DSF and OS, were similar in both groups during a mean follow-up period of 42 months (range: 3-138 months). $(4,7 \%)$.

In group A, 11 uterine perforations were recorded during surgery

Table 1. Characteristics of the populations compared. All results are presented in absolute numbers and percentages, unless otherwise specified

\begin{tabular}{|c|c|c|c|}
\hline Variable & Group A $\quad N=232$ & Group B $\quad N=47$ & P value \\
\hline Age (mean in years) $\pm \mathrm{SD}$ & $63,5 \pm 29,6$ & $63,6 \pm 6,3$ & NS \\
\hline Mean BMI \pm SD & $30,16 \pm 2,9$ & $30,12 \pm 4,7$ & NS \\
\hline $\begin{array}{l}\text { Histological type } \\
\text { Type I } \\
\text { Type II }\end{array}$ & $\begin{array}{c}191(82,3 \%) \\
41(17,7 \%)\end{array}$ & $\begin{array}{l}37(78,7 \%) \\
10(21,3 \%)\end{array}$ & $\begin{array}{l}\text { NS } \\
\text { NS }\end{array}$ \\
\hline $\begin{array}{c}\text { Pre-surgery stage } \\
\text { I } \\
\text { II } \\
\text { III } \\
\text { IV }\end{array}$ & $\begin{array}{c}208(89,6 \%) \\
7(3,0 \%) \\
15(6,6 \%) \\
2(0,8 \%)\end{array}$ & $\begin{array}{c}35(74,4 \%) \\
3(6,4 \%) \\
7(14,9 \%) \\
2(4,3 \%)\end{array}$ & $<0,005^{*}$ \\
\hline $\begin{array}{c}\text { Post-surgery stage } \\
\text { I } \\
\text { II } \\
\text { III } \\
\text { IV }\end{array}$ & $\begin{array}{c}182(78,4 \%) \\
8(3,4 \%) \\
39(16,9 \%) \\
3(1,3 \%)\end{array}$ & $\begin{array}{c}34(72,3 \%) \\
3(6,4 \%) \\
7(14,9 \%) \\
3(6,4 \%)\end{array}$ & NS \\
\hline $\begin{array}{c}\text { Type of surgery } \\
\text { TH + BSO } \\
\text { TH }\end{array}$ & $\begin{array}{c}227(97,8 \%) \\
5(2,2 \%)\end{array}$ & $\begin{array}{c}45(95,7 \%) \\
2(4,3 \%)\end{array}$ & NS \\
\hline $\begin{array}{c}\text { Pelvic lymphadenectomy } \\
\text { Yes } \\
\text { No }\end{array}$ & $\begin{array}{l}109(47,0 \%) \\
123(53,0 \%)\end{array}$ & $\begin{array}{l}24(51,0 \%) \\
23(49,0 \%)\end{array}$ & NS \\
\hline $\begin{array}{c}\text { Paraaortic lymphadenectomy } \\
\text { Yes } \\
\text { No }\end{array}$ & $\begin{array}{l}29(12,5 \%) \\
203(87,5 \%)\end{array}$ & $\begin{array}{c}8(17 \%) \\
39(83 \%)\end{array}$ & NS \\
\hline $\begin{array}{c}\text { Intraoperative complications } \\
\text { Yes } \\
\text { No }\end{array}$ & $\begin{array}{c}22(9,5 \%) \\
210(90,5 \%)\end{array}$ & $\begin{array}{c}6(12,7 \%) \\
41(87,3 \%)\end{array}$ & NS \\
\hline
\end{tabular}

SD: Standard Deviation; NS: Not significative; BMI: Body Mass Index; TH: Total Hysterectomy; BSO: Bilateral Salpingooophorectomy; *: Statistical Significance

Table 2. Oncological outcomes. All results are presented in absolute numbers and percentages, unless otherwise specified

\begin{tabular}{|c|c|c|c|}
\hline Variable & Group A $\quad N=232$ & Group B $\quad N=47$ & P value \\
\hline $\begin{array}{c}\text { Adjuvant treatment } \\
\text { Yes } \\
\text { No }\end{array}$ & $\begin{array}{l}115(49,5 \%) \\
117(50,5 \%)\end{array}$ & $\begin{array}{l}31(65,9 \%) \\
16(34,1 \%)\end{array}$ & $<0,05^{*}$ \\
\hline $\begin{array}{l}\text { Recurrence } \\
\text { Yes } \\
\text { No }\end{array}$ & $\begin{array}{c}34(14,6 \%) \\
198(85,4 \%)\end{array}$ & $\begin{array}{c}5(10,6 \%) \\
42(89,4 \%)\end{array}$ & NS \\
\hline $\begin{array}{l}\text { Death } \\
\text { Yes } \\
\text { No }\end{array}$ & $\begin{array}{c}19(8,2 \%) \\
213(91,8 \%)\end{array}$ & $\begin{array}{c}2(4,2 \%) \\
45(95,8 \%)\end{array}$ & NS \\
\hline DFS (in months) & $39,14 \pm 5,6$ & $39,03 \pm 2,1$ & NS \\
\hline OS (in months) & $42,3 \pm 5,6$ & $42,3 \pm 0,7$ & NS \\
\hline
\end{tabular}

DFS: Disease Free Survival; OS: Overall Survival; NS: Not Significative. *: Statistical Significance 


\section{Discussion}

In our results, we found no differences in oncological outcomes between the patients in whom we used the uterine manipulator and those in whom we did not use it. Our results are in agreement with several recently published studies.

In the clinical trial by Lee et al. [7], in which 110 patients with stage I endometrial carcinoma were included and randomized to the use of the manipulator $(\mathrm{n}=55)$ or to the non-use of the manipulator $(\mathrm{n}=55)$ the did not find differences between both groups in positive cytological peritoneal washes or lymphovascular space invasion. In this study, they used the RUMI manipulator. Similar results were reported in the study by Tinelli et al. [8], in which no higher rate of positive peritoneal cytologies lymphovascular space invasion was found among patients in whom a uterine manipulator was used.

In a prospective, multicentre study in which 7 Italian hospitals participated, 951 patients surgically treated for endometrial cancer were recruited: 579 patients in whom a uterine manipulator was used and 372 in whom it was not used. The results of the study showed no differences between both groups and the authors concluded that the use of the uterine manipulator is safe during surgery for endometrial cancer [9]. In the study by Alleti et al. [10], 154 patients with lowrisk endometrial carcinoma were randomized to use the manipulator during surgery $(n=78)$ or to non-use $(n=76)$. The data showed that the intrauterine manipulator does not affect the perioperative and oncological outcomes of presumed low-risk endometrial cancer patients undergoing laparoscopic/robotic staging.

A recent meta-analysis that included 11 studies concluded that: (i) the timing of uterine manipulators insertion during minimally invasive surgery for endometrial cancer was not associated with an increased risk of positive peritoneal cytology (RR: $1.21,95 \%$ CI, 0.68 to 2.16) (ii) there was no significant difference for the rate of positive peritoneal cytology (RR: $1.53,95 \% \mathrm{CI}, 0.85$ to 2.77 ), LVSI (RR: $1.18,95 \% \mathrm{CI}$, 0.66 to 2.11 ) or the rate of recurrence (RR: $1.25,95 \% \mathrm{CI}, 0.89$ to 1.74 ) regarding the use of uterine manipulators for laparoscopic surgery in the treatment of endometrial cancer patients [11].

On the other hand, some studies do not recommend the use of the uterine manipulator. In a prospective study with 46 patients, in which peritoneal washing and cytology were performed before inserting the uterine manipulator, after its insertion and after removal of the uterus through the vagina, it was found that the use of the uterine manipulator was associated with a higher rate of positive peritoneal cytologies [12]. A retrospective, multicentre study carried out in Spain in which data were collected from 2,661 patients, of which 1,756 underwent hysterectomy with a uterine manipulator and 905 without it, found worse oncological results among the first patients: recurrence rate of $11.69 \%$ versus $7.4 \%$, lower disease-free survival and higher risk of death [13].

Among the causes that would explain the worst oncological results are the increase in intrauterine pressure and the risk of perforation of the uterus. In our series, 11 perforations occurred in 232 procedures $(4,7 \%)$. In the study of Machida et $\mathrm{al}^{14}$, a total of 333 patients were included, cases were divided into those with intrauterine manipulator insertion after pelvic cytology sampling (Group 1, $\mathrm{n}=103$ ) and those with intrauterine manipulator insertion before pelvic cytology sampling (Group 2, $\mathrm{n}=230$ ). Uterine perforation related to intrauterine manipulator insertion was seen in $1.0 \%$ and $4 \%$ of each group $(\mathrm{p}=.52)$. Uterine perforations did not lead to an increased risk of recurrence.

Our study has some limitations. The risk of selection bias may be present in this retrospective study. In our series, we have included low and high-risk endometrial carcinomas, which could influence survival results regardless of the use of the manipulator.

In conclusion, our results confirm that the uterine manipulator can be used safely during surgery for endometrial carcinoma.

\section{Funding}

For this study, we have not received any type of funding

\section{Conflict of interests}

The authors declare no conflict of interest

\section{References}

1. Siegel RL, Miller KD, Jemal A (2020) Cancer statistics, 2020. CA Cancer J Clin 70: 7-30. [Crossref]

2. Colombo N, Creutzberg C, Amant F, Bosse T, González-Martín A, et al. (2016) ESMOESGO-ESTRO Consensus conference on endometrial cancer: diagnosis, treatment and follow-up. Int J Gynecol Cancer 26: 2-30. [Crossref]

3. Eltabbakh GH, Shamonki MI, Moody JM, Garafano LL (2001) Laparoscopy as the primary modality for the treatment of women with endometrial carcinoma. Cancer 91 : 378-387. [Crossref]

4. Khalek YA, Bitar R, Christoforou C, Garzon S, Tropea A, et al. (2020) Uterine manipulator in total laparoscopic hysterectomy: safety and usefulness. Updates Surg 72: 1247-1254. [Crossref]

5. Ramirez PT, Frumovitz M, Pareja R, Lopez A, Vieira M, et al. (2018) Minimally invasive versus abdominal radical hysterectomy for cervical cancer. $N$ Engl J Med 379: 1895-904. [Crossref]

6. Dietl A, Klar M, Aumann K (2019) Minimally invasive surgery for early-stage cervical cancer: is the uterine manipulator a risk factor? Am J Obstet Gynecol 21: 537-538. [Crossref]

7. Lee M, Kim YT, Kim SW, Kim S, Kim JH, et al. (2013) Effects of uterine manipulation on surgical outcomes in laparoscopic management of endometrial cancer: a prospective randomized clinical trial. Int J Gynecol Cancer 23: 372-379. [Crossref]

8. Tinelli R, Cicinelli E, Tinelli A, Bettocchi S, Angioni S, et al. (2016) Laparoscopic treatment of early-stage endometrial cancer with and without uterine manipulator: Our experience and review of literature. Surg Oncol 25: 98-103. [Crossref]

9. Uccella S, Bonzini M, Malzoni M, Fanfani F, Palomba S, et al. (2017) The effect of a uterine manipulator on the recurrence and mortality of endometrial cancer: a multicentric study by the Italian Society of Gynecological Endoscopy. Am J Obstet Gynecol 216: 592.e1-592.e11. [Crossref]

10. Alletti SG, Perrone E, Fedele C, Vizzielli G, Fagotti A, et al. (2020) A multicentric randomized trial to evaluate the role of uterine manipulator on laparoscopic/robotic hysterectomy for the treatment of low-risk endometrial cancer: the ROMANHY trial (NCT: 02762214). Int J Gynecol Cancer 30 (Suppl 3): AA5-AA7.

11. Meng Y, Liu Y, Lin S, Cao C, Wu P, et al. The effects of uterine manipulators in minimally invasive hysterectomy for endometrial cancer: A systematic review and meta-analysis. Eur J Surg Oncol 46: 1225-1232.

12. Lim S, Kim HS, Lee KB, Yoo CW, Park SY, et al. (2020) Does the use of a uterine manipulator with an intrauterine balloon in total laparoscopic hysterectomy facilitate tumor cell spillage into the peritoneal cavity in patients with endometrial cancer? Int $J$ Gynecol Cancer 18: 1145-1149. [Crossref]

13. Padilla-Iserte P, Lago V, Tauste C, Díaz-Feijoo B, Gil-Moreno A, et al. (2020) Impact of uterine manipulator on oncological outcome in endometrial cancer surgery. Am J Obstet Gynecol 1: 65.e1-65.e11. [Crossref]

14. Machida H, Casey JP, Garcia-Sayre J, Jung CE, Casabar JK, et al. (2016) Timing of intrauterine manipulator insertion during minimally invasive surgical staging and results of pelvic cytology in endometrial cancer. J Minim Invasive Gynecol 23: 234241. [Crossref]

Copyright: (C2021 Cuadra M. This is an open-access article distributed under the terms of the Creative Commons Attribution License, which permits unrestricted use, distribution, and reproduction in any medium, provided the original author and source are credited. 